\title{
A New Theory of Wisdom: Integrating Intelligence and Morality
}

\author{
Wang Fengyan, Zheng Hong \\ Nanjing Normal University, Nanjing, China
}

\begin{abstract}
This paper presents a new concept of wisdom, which integrates intelligence and morality as its two constituent elements. According to our definition, wisdom is a mental capacity of combining intelligence with moral virtue in the process of gaining knowledge and acting. Possessing this integrated quality, an individual would be able to act wisely when faced with complex situations. On the one hand, moral virtue provides one with the motivation to do well. It is the very source of autonomously keeping his own action in conformity with the moral standards. On the other hand, equipped with the mental capacity of intelligence, the agent is able to arrive at correct judgments about the complex problem he/she is facing and comes up effectively and efficiently with a solution to it. The integrated quality of having intelligence and moral virtues guarantees that the proposed solution and the corresponding act will benefit the well-being of the individual herself/himself and others. In accordance with the two-element definition of wisdom, we classify wisdom into moral wisdom and natural wisdom, which will be elaborated in this paper.
\end{abstract}

Keywords: wisdom, moral wisdom, natural wisdom, quasi-wisdom, true wisdom

\section{Why a New Theory of Wisdom?}

We are motivated by the following five reasons for proposing a two-element model of wisdom, which is quite different from the traditional views.

\section{Firstly, to Explicate the Nature of Interconnectedness Between Intelligence and Morality}

The interconnection between one's intelligence and moral virtue can be seen in two ways. From the positive perspective, having moral virtue contributes to the development of intelligence. From the negative perspective, lacking moral virtue will have a negative effect on intelligent growth, and vice versa.

The positive perspective. Wisdom combines morality and intelligence into a unity in such a way as to make the two elements reinforce each other. Most psychologists define intelligence as a very general capability that, among other things, involves the ability to reason, plan, solve problems, think abstractly, understand complex ideas, learn quickly and learn from experience (Grieg \& Zimbardo, 2003, p. 264). Under such a definition, an individual with high-level IQ (intelligence quotient) is able to gain knowledge about natural and social sciences more efficiently. Equipped with that knowledge, the individual, a natural mechanism subject to the natural laws, can nevertheless utilize it for his own welling. This contributes to the establishment of his own

*This article was supported by the key research center funding of Humanities and Social Science of Ministry of Education (Grant No.: 07JJD880241; 12JJD880012) and the key items of ministry of education of the national education science's eleventh-five year plan (Grant No. DEA070061) in China.

Wang Fengyan, Ph.D., professor, College of Educational Sciences, Nanjing Normal University.

Zheng Hong, Ph.D., associate professor, College of Educational Sciences, Nanjing Normal University. 
autonomy, freedom and wisdom.

However, with a moral character trait, people can have their intelligence developed more effectively. As a remark in Guanzi goes, "Good intelligence results from good morality” ( $\mathrm{Li}, 2004$, p. 931). Moral virtue promotes the development of intelligence in three ways:

(1) Developing individuals' crystallized intelligence with a virtue of lifetime learning. According to the theory of fluid and crystallized intelligence (Cattell, 1963; Horn, 1965; Horn \& Cattell, 1966, 1967), intelligence is constituted by fluid intelligence and crystallized intelligence. Fluid intelligence refers to those innate abilities that a person is born with. Crystallized intelligence is a person's abilities acquired through crystallizing his own experiences. It builds on fluid intelligence and is gradually developed through experience of learning languages, mathematics, or other subjects. A person with higher fluid intelligence will develop higher crystallized intelligence than those who have the same experience but have lower fluid intelligence. A person with higher fluid intelligence, if living in a poor learning environment, will develop crystallized intelligence at a low level.

Horn and Cattell (1967) also found that fluid intelligence varies with age. It reaches the peak at around 20 years old, and maintains at that level into 30 years old. From 30 years old onward, it begins to decline gradually, and reaches the lowest level at one's 60 years old. This finding implies that if a person with high fluid intelligence does not continue learning as he grows older, his intelligence will decline to an average level (Horn \& Cattell, 1967, pp. 107-129; Huang, 2007, pp. 539-548). Fang Zhongyong is a typical example, as described in an article titled A Pity for Zhongyong by Wang Anshi (1021-1086). Generally speaking, if a person does not develop a good habit of continuous learning, he/she will not be able to develop crystallized intelligence to a satisfactory level. On the contrary, a hardworking person often achieves the best learning result.

(2) Promoting individuals' intelligence by resisting greedy temptation. Greed is a vice and could make an individual lose his ability to make correct judgments and choices. It could become a possible barrier to the development of one's intelligence, as an old Chinese saying goes, "Greedy makes stupid”. Moral virtue can effectively resist greedy temptation, help to avoid its negative effects on reasoning and benefit the development of intelligence.

(3) Enhancing individuals' emotional intelligence with the virtue of temperance. The emotional intelligence refers to the ability to perceive, appraise and express emotions accurately, and adapt emotions to the changing context. Positive emotions can contribute to the development of intelligence by making one think and reason more intelligently. High emotional intelligence helps a person understand well the possible impacts of his emotions on others (Grieg \& Zimbardo, 2003, p. 271). On the contrary, negative emotions disturb one's normal reasoning. A virtue of temperance helps one to develop emotional intelligence.

The negative perspective. On the one hand, the lack of moral virtue will hinder the development of individuals' intelligence. Historically, it had been proved that those with intelligence but without moral virtue eventually become victims of their own intelligence. On the other hand, a person with a very low level of intelligence, say, a mentally retarded person, will have difficulty on both "zuòrén"1 and "zuòshì"” because he cannot have a full understanding of "zuòrén” and "zuòshì” and how to achieve these effectively. Due to his low

\footnotetext{
${ }^{1}$ In Chinese culture, “zuòrén” (做人, being a person), means to act in a morally wise way which differentiates human beings from animals.

${ }^{2}$ In Chinese culture, “zuòshì” (做事) means “doing things”. If the person acts in a morally wise way, he integrates doing with being. This is the essence of a moral person.
} 
intelligence, he cannot gain much knowledge about the natural world either. As a result, he will have a very low level of wisdom, intelligent or moral.

\section{Secondly, to Explicate Different Perspectives on the Notion of Wisdom of Chinese and Western Cultures}

Different cultures usually have diverse views on the notion of wisdom. While they share common views among them, each has its own unique insights. This is particularly the case when it comes to Chinese and Western traditions. Ancient Chinese thought that wisdom was mainly embodied in one's ability to understand the human nature. As Mencius (372 B.C.-289 B.C.) wrote,

He who has exhausted all his mental constitution knows his nature. Knowing his nature, he knows heaven. To preserve one's mental constitution and nourish one's nature is the way to serve heaven. (James Legge, 1991, pp. 448-449)

On this view, a person will be regarded as wise, if he/she is good at understanding human nature and employing this knowledge for the well-being of the general public (Lin, 2005, p. 20). In Chinese tradition, "wisdom of zuòrén" (that is, wisdom on how to become a virtuous person), is much more emphasized than "wisdom of zuòshì" (i.e., wisdom on how to do things practically). Moral wisdom is taken to be more important than natural wisdom in Chinese culture.

In contrast, the Western tradition tends to hold that wisdom is primarily embodied in understanding nature. If a person is good at grasping and discovering the laws of nature, or good at employing natural laws for inventions, and befitting the public well-being, he/she will be taken to be wise. In western culture, wise people, such as Newton and Einstein, are expected to be good at achieving remarkable understanding of the natural world, and knowledge attained in this way should be able to promote public well-being (Lin, 2005, p. 20). These people are well-known scientists who have great accomplishments in natural science, but they are not philosophers. This fact does not mean that Western cultures have ignored the moral dimension of wisdom. On the contrary, "wisdom of zuòrén" is also being stressed by the West, which has its origin in Christianity. It should be noted, however, that while the Western tradition has both the notion of "wisdom of zuòshì" and the notion of "wisdom of zuòrén", it tends to give more attention to the latter than the former, because it focuses on the task of exploring the natural world.

Emphasizing different elements of wisdom, Chinese and Western traditions should complement each other. Moral virtue should be given equal weight with intelligence. In this way, the appropriate account of wisdom can be guaranteed, and the insights from different traditions will be well preserved.

\section{Thirdly, to Capture the Shared Elements in the Traditional Chinese and Western Concepts of Wisdom}

Baltes and Staudinger (1993, p. 76) defined wisdom as an expert knowledge system in the fundamental pragmatics of life permitting exceptional insight, judgment and advice involving complex and uncertain matters of the human condition. As they put it, "Wisdom involves good intentions. It is used for the well-being of oneself and others” (Baltes \& Staudinger, 2000, p. 123). Sternberg (2004c, p. 287) defined wisdom as application of intelligence, creativity and knowledge to the common good by balancing intrapersonal (one's own), interpersonal (others') and extrapersonal (institutional or other larger) interests over the long and short terms, through the mediation of values, so as to adapt to shape and select environments. Both the Berlin model and Sternberg's view integrate intelligence with morality in their definitions of wisdom. But the Chinese model of wisdom expresses even more clearly the idea of integrating intelligence with morality in wisdom (Wang \& Zheng, 2009, pp. 104-110). This shows that, while China and the West differ in the conception of wisdom, they 
are united in the thought that wisdom is the organic unity of morality and intelligence.

\section{Fourthly, to Promote the Education of Wisdom}

Ever since Sternberg proposed that school should "teach for wisdom” (Sternberg, 2001a, pp. 227-245), there have been a lot of controversies. Some opponents believe that wisdom is usually based on post-formal or dialectical reasoning and acquired only through experience (Paris, 2001, p. 258). On their views, one begins to acquire wisdom-related knowledge only at the stage of late adolescence and early adulthood (Baltes \& Smith, 2008, p. 60). Therefore, wisdom cannot be taught for children until they grow into adulthood.

Sternberg (2001b, p. 271) responded to these criticisms by arguing that it will be too late for us to begin to teach children wisdom at adulthood. He pointed out that children of any age would not be too young to conceive their relations with others and to develop sense of values and of responsibility.

From Paris' criticisms and Sternberg's responses, we can see that both of the two sides make the same mistake: They fail to see that wisdom has multiple components, and thus education of wisdom should have multiple levels too. As a matter of fact, we can take the cultivation of quasi-wisdom to be the main aim of childhood wisdom education. Then, the cultivation of true wisdom should become the main aim of wisdom education as they mature gradually, accumulate experiences and gain more and more explicit knowledge and tacit knowledge.

\section{Fifthly, to Clarify the Relationship Between Wisdom and Wise Person}

The relationship between wisdom and wise person should be clarified. The two concepts are connected in that wisdom is embodied in a wise person's behaviors, and one with wisdom is a wise person. The differences between the two concepts are: (1) They have different characteristics. Wisdom is a kind of psychological phenomenon, while wise person is the person who owns the wisdom; and (2) There is no one-to-one corresponding relationship between them. If one acts wisely on some occasions but not always, he should not be considered as a true wise person. Only a person often shows wisdom on all occasions, he can be said to be wise.

\section{The Outline of the New Theory of Wisdom}

Our new conception of wisdom consists of a novel definition of wisdom and a new classification of wisdom.

\section{A Novel Definition of Wisdom by Integrating Intelligence and Morality}

We define wisdom as a general mental capacity of integrating intelligence with morality, which is acquired by experience and practice. It helps individuals who have such a capacity to act wisely in a complex situation: Under the guidance of conscience and proper motivation, individuals can make full use of their intelligence to recognize and understand the complex problems facing them and come up with solutions to these problems innovatively and efficiently, which tend to promote common good. We should understand the nature of wisdom, distinguish wisdom from knowledge and intelligence and identity the factors contributing to the development of wisdom (Wang \& Zheng, 2011, p. 306).

Wisdom consists of intelligence and morality. Many people are unclear about the connections and differences among the concepts of wisdom, instinct, intelligence and knowledge. They tend to equate wisdom with high IQ (cleverness) or knowledge. Besides, Sternberg (1998; 2001b; 2003; 2004c, p. 287) who distinguished wisdom from intelligence and knowledge clearly, there are also many other theories on these concepts and their relations. For instance, ancient Chinese proposed that, "Wisdom is derived from 
knowledge” (Wang \& Zheng, 2009, pp. 104-110); Piaget proposed a theory of intelligence (Piaget, 1992, pp. 5-10); Erikson developed a view of wisdom (Erikson, 1959); There is the Berlin model of wisdom (Baltes \& Staudinger, 1993, pp. 76-77; Baltes \& Staudinger, 2000, pp. 123-125); and There is Neo-Piagetian view of wisdom (Sternberg, 1998, p. 350). But all of these theories fail to capture the true nature of wisdom in that they mistakenly equate wisdom with a kind of ability, or knowledge, or a way of thinking (Wang \& Zheng, 2010, pp. 93-97).

Wisdom consists mainly of six components: knowledge, explicate and tacit, cognition (meta-cognition included), ways of thinking, character traits (such as tolerance and volition), affection and good will (Sternberg, 1998, p. 350). As Locke (1632-1704, 1999, p. 117) put it, "I agree with the popular view of wisdom: Wisdom is a capacity that enables one to do things efficiently. It results from a combination of moral virtues of heart and experience”. So, Locke thought that wisdom has intelligence and morality as its two constituents.

The moral constituent of wisdom involves three elements of goodness: (1) having a good will, the will to serve the common good; (2) acting morally. The acts taken by a wise person should comply with moral principles; and (3) having good consequences. A wise act should have the consequences of promoting the common good. The more elements of goodness an act contains, the wiser it is. Where there is no goodness there is no wisdom.

There is no doubt that moral conventions are culturally relative in that different cultures have adopted differing moral standards. But, they share common moral principles, which are not relative to culture but are universal. Since wisdom has moral virtue as one of its constituents, it is thus both relative to culture and universal. The universal principles that wisdom adopts include: (1) the principle of benevolence. This principle can be found in the Confucian concept of benevolence, the Taoist concept of kindliness, the Mohist notion of universal love, and the notion of charity of Buddhism and western culture. Its core idea is to maximize mutual love among people; (2) the principle of justice. This principle can be found in Kant's notion of justice, which maintains that a person should respect other person's autonomy and dignity, and treat others as an end instead of a means; and (3) the utilitarian principle. This principle comes from John Stuart Mill's principle of the greatest utility. It identifies goodness of an act with its capacity of promoting the greatest happiness for the greatest number, or equivalently, of reducing the pain to a minimum (Kohlberg, 1984, p. 526). The more principles are embodied in an act, the wiser is the act.

Wisdom has intelligence and morality as its two components, and finds its role both in dealing with daily-life problems and in scientific inquiry. This means that intelligence and moral virtue not only can be applied to everyday life situations, but also can be used in scientific investigation. So, wisdom has a broader scope of application than people might think.

The interrelation between wisdom and knowledge. One of the components of wisdom is procedural knowledge, which can be meta-cognitive or tacit. Procedural knowledge can be divided further into pure cognitive knowledge and moral knowledge (accompanied naturally by affection and good will). A person attains procedural knowledge mainly by learning and doing, and thus, it is a mental capacity acquired from experience. The innate abilities that one is born with doing not belong to wisdom, but belong to instinct.

The intimate connection between wisdom and knowledge is as follows: One of the ingredients of wisdom is knowledge. Wisdom gradually obtains by means of "transforming knowledge” (Wang \& Zheng, 2009, pp. 104-110). Once wisdom is established, it can further promote accumulation of knowledge. As Whitehead (1861-1947, 2002, p. 54) remarked, 
Wisdom is the means of mastering knowledge. It refers to the process of mastering knowledge and employing knowledge to solve problems. It makes our intuitive experience more valuable by making use of our knowledge. The mastery of knowledge is wisdom.

In Whitehead's view, wisdom becomes established only on the basis of knowledge. Wisdom shows itself in the appropriate employment of knowledge to solve problems.

There are four important differences between wisdom and knowledge: (1) Knowledge can be both declarative and procedural, while wisdom by its nature is only of procedural knowledge; (2) Knowledge in itself can be of value or no value, but knowledge leading to wisdom necessarily has great value; (3) Knowledge is about particular facts and usually takes the form of theorem, but wisdom tends to be about the truth of general things (Feng, 1996, pp. 418-420). As Aristotle (384-322 BC, 1959, pp. 2-3) put, "(wisdom is derived from general knowledge, not the individual realization.)... Wisdom is knowledge about principles and causes". Equipped with wisdom, one is able to grasp the nature and laws of things. He/she who masters the laws of things and uses the knowledge to produce common good is a wise person; and (4) Although knowledge includes knowledge of natural science and knowledge of morality, its nature is fundamentally cognitive. Wisdom brings intelligence and morality together as its two essential elements, and is of normative nature.

The differences between the two concepts show that, while a knowledgeable person could have high-level wisdom, wisdom and knowledge are surely not the same thing. As Heraclitus (about 540-480 B.C., Selected Works of Western Philosophy, 1981, p. 26) put, “abundance in knowledge cannot guarantee wisdom”. Being knowledgeable only means having knowledge, but being wise means much more than that. A person with lots of knowledge in science and technology but without knowing how to be an upright person, for example, is not likely to establish his/her wisdom. A person having access to only outdated knowledge cannot have wisdom developed either. It is even the case that, the more outdated knowledge he/she accumulates, the more stupid he/she could be. A person who has much declarative knowledge but cannot transform it into procedural knowledge is not likely to possess tacit knowledge. He/she could only process knowledge having existed in memory but cannot achieve innovation. In this sense, he/she is merely a "moving bookshelf". But a person who possesses procedural knowledge and knows how to use it innovatively still cannot develop wisdom, if he/she uses it only for his/his own self-interest but not for common good. This can be seen clearly from the case of Hitler (Sternberg, 1998; 2004b; 2004c).

In conclusion, one can acquire wisdom only if he/she possesses and uses all sorts of valuable knowledge creatively and for common good. Valuable knowledge here includes knowledge of how to be a morally virtuous person, scientific knowledge, declarative knowledge and procedural knowledge. Wisdom cannot be equated with expert knowledge as Baltes advocated (Baltes \& Staudinger, 1993, pp. 75-80), nor can it be taken to be merely explicit knowledge. The important role of tacit knowledge in the development of wisdom should not be neglected (Sternberg, 1998, 2004c; Wang \& Zheng, 2008, pp. 272-273).

Creativity is one of the important features of wisdom. In Sternberg's view, wisdom includes creativity (Sternberg, 2004c, p. 287). According to the Berlin model of wisdom (Baltes \& Staudinger, 1993, p. 76), wisdom is an expert knowledge system, the professional ways of solving problems innovatively, effectively and efficiently. Common sense holds that knowledge acquisition relies on the role of memory. This implies that wisdom has the element of memorization. But, wisdom means much more than memorization. Different from mere memorization or mere application of familiar concepts and principles to new problems, wisdom essentially involves creativity, and people cannot develop new concepts, new principles and new strategies of 
problem-solving merely by memorizing. Creativity must be called upon for new knowledge to be acquired. It forms one of the essential features of wisdom.

To identify the connection between wisdom and intelligence. Psychologist studies have shown that there is a non-linear relationship between intelligence and creativity. They are independent from one another, but are related under certain circumstances (Huang, 2005, pp. 217-218). There is a similar relationship between wisdom and intelligence: Firstly, since it is impossible for low-IQ persons to have high creativity, it is impossible for these people to develop high wisdom; Secondly, high-IQ persons may either have high-level creativity or low-level creativity. Accordingly, they may either have high wisdom or low wisdom; Thirdly, a person with low creativity may either have high IQ or low IQ, so a person with low wisdom may either have high IQ or low IQ; Finally, since a person with high creativity must have high IQ, a person with high wisdom must also have high IQ. The reason is that wisdom contains both creativity and morality.

On the other hand, intelligence and wisdom are different things, although they are mistakenly taken to be equivalent in most dictionaries. Ordinary people also confuse the two terms and use them interchangeably, as if they had the same meaning. However, there are three important differences between the two concepts as follows.

(1) They are different in meaning. In English, "intelligence" means an inborn mental capacity, a capacity that one is born with and is independent of his culture and experiences. "Wisdom" refers to a mental capacity that is acquired through learning (Lu, 1993, p. 915, p. 2186). Since learning necessarily takes place in a certain culture, wisdom resulting from learning tends to be relative to culture.

(2) High IQ only refers to cleverness, but wisdom integrates cleverness with morality. Some contemporary psychologists have expanded the connotation of intelligence, as they developed such diverse concepts as social intelligence, emotional intelligence, interpersonal and intrapersonal intelligences by having added a dimension of emotion and morality to "intelligence". But the added compositions do not fundamentally change the traditional meaning of intelligence. Since morality is treated as different in kind from intelligence in the Western tradition (Yang \& Sternberg, 1997, p. 112), intelligence tends to be a morally neutral term and high IQ refers only to cleverness. But, wisdom is actually a normative term which integrates intelligence with morality (Sternberg, 1998, pp. 359-360).

(3) They have different impacts on an individual's accomplishments and happiness, as well as on the progress of civilization. Some studies showed that intelligence contributes significantly to an individual's success and happiness (Sternberg, 1998; Wang \& Zheng, 2008). Wise people are more likely to be successful and live a happy life than their unwise counterparts. With the good intention to promote the well-being for all, their acts in turn have positive impacts on the progress of the civilization in which they live. This is one of the reasons why contemporary psychologists turn away from intelligence and instead focus their attentions on wisdom as the object of inquiry.

To identify the relation between wisdom and method of thinking. While thinking wisely involves the method of formal-operational thinking or that of post-formal-operational thinking proposed by Piaget and his followers (Sternberg, 1998, p. 350), it cannot be reduced to it. The multiple nature of wisdom determines that thinking wisely involves diverse methods of thinking.

The development of wisdom is influenced by heredity, environment, education and efforts. (1) Heredity and maturation are two important factors which influence the genesis and development of wisdom. Intelligence is one of the important factors that influence the genesis and development of wisdom. 
Psychological studies show that heredity and maturation are biological basis for the normal development of intelligence. Heredity constitutes the natural condition for the genesis and development of intelligence, without which there would be no intelligence. Meanwhile, morality is the other important factor that contributes to the generation and development of wisdom. If the theory of heredity in evolutionary biology is correct, we can reasonably suppose that emotional traits can also be inherited by the next generation. For example, some people tend to possess more sympathy than others since birth. Inherited traits of respecting moral principles make one more likely develop moral virtues if trained properly. People not only inherit the general quality of fear, but also inherit fear of specific things, such as darkness and snakes. Of course, this does not mean that human beings have inborn moral emotions. Rather, it merely means that they are more likely to pick up those qualities that were possessed by their parents. Therefore, we should not deny the heritability of moral emotions on the one hand, and be aware that their development depends on education and experience on the other hand. Moral virtues need external factors for their development, just as other human instincts do. But, we should not deny that these instinct qualities can be inherited (Thilly, 1987, pp. 67-69).

(2) Environment and education play an important role in the development of wisdom. Environment and education also influence the genesis and development of wisdom in a person. The environment here includes the fetal environment, family environment, natural environment and social environment. The education here includes different levels and types of school education as well as an individual's self-education. It is by various kinds of education and experiences that individuals acquire explicit and tacit knowledge. Generally speaking, individuals with certain genetic qualities would develop high-level wisdom, if they are well educated and live in a moral environment.

(3) Self-effort is another important factor that helps the development of wisdom. From the standpoint of Marxist dialectical materialism, compared with the primary role of internal factors, external factors play only a secondary role in the happening of something, which is fulfilled only through the functioning of internal factors. According to this principle, the genesis and development of wisdom is neither a natural process of individuals' innate ability, nor a direct psychological change caused by external factors, but a change of psychological structure caused by the interaction between the individual and the environment. His/her efforts devoted to the development of wisdom play a pivotal role.

\section{Moral Wisdom and Natural Wisdom: A New Classification}

Corresponding to different kinds of abilities of wisdom, wisdom can be divided into moral wisdom and natural wisdom.

Definitions of moral wisdom and natural wisdom. We define moral wisdom as a comprehensive mental capacity of integrating intelligence with morality, which is acquired through experience and practice based on intelligence and knowledge (mainly the knowledge of being an upright person) and which helps individuals with such a capacity to act in the following way when faced with a complex situation: Under the guidance of their intelligence and good intention, they are able to understand the moral implications of the problem faced with them and come up with a solution in correct, innovative, quick, ingenious, efficient and moral ways. The corresponding acts they take will tend to increase common good in the long run. In Mozi’s (about 468-376 B.C.) view, "Loving people contains loving oneself" (Sun, 2001, p. 405). Moral wisdom is thus an ability to understand the nature of the self and the responsibilities to others.

We define natural wisdom as a comprehensive mental capability of integrating intelligence with morality, 
which is acquired by experience and practice based on individuals' intelligence and knowledge (mainly the knowledge of natural science), and which helps individuals with such a quality to act in the following way when faced with a complex situation: Under the guidance of their intelligence and good intention, they are able to recognize and understand the complex scientific problems faced with them, and come up with a solution in correct, innovative, quick, ingenious, efficient and moral ways. The corresponding acts they take will tend to increase common good in the long run (Wang \& Zheng, 2011, pp. 309-310).

The differences between moral wisdom and natural wisdom. There are four differences between moral wisdom and natural wisdom.

(1) The distinction between moral wisdom and natural wisdom corresponds to different characteristics of abilities. Moral wisdom is mainly reflected in the process of solving problems of "zuòrén". A person can be considered to be morally wise, if she is always able to propose innovative, efficient, ingenious and moral solutions to problems of "zuòrén", which tends to increase common good via corresponding acts. Natural wisdom is mainly reflected in the process of solving problems of "zuòshì". A person can be considered to have natural wisdom, if she is always able to come up with innovative, efficient, clever and moral solutions to problems of "zuòshì", which tends to promote the common good. The distinction between the two kinds of wisdom corresponds to two different sorts of abilities: abilities of moral thinking and abilities of scientific thinking.

(2) The primary properties of moral wisdom and natural wisdom are different. The primary element of moral wisdom is morality, and the secondary element is creativity. We can use a mathematical formula to show how the two elements contribute to moral wisdom: $W m=M \times C w$, where "Wm" stands for "moral wisdom", " $M$ " for "motivation", “ $C w$ " for "creativity in wisdom" meaning creativity in problem solving of zuòrén; and “ $x$ " is multiplication. With the same level of creativity, a person with higher motivation to solve problem of "zuòrén” will develop moral wisdom to a higher level. But, the requirement of creativity in problem solving of "zuòrén" is not strict and a modest level of creativity will do (of course, the more creativity, the better). A person with a high level of motivation but without the ability of creativity in problem solving of "zuòrén" is only a morally good person but not one of moral wisdom, because, as indicated in the formula, the product of moral wisdom, "Wm", must be zero, whenever there exists a zero motivation, no matter how large the number of creativity, " $C w$ ", is.

There is also a criterion by which to judge whether a person has natural wisdom. It is to see if he/she can use innovative, efficient and ingenious ways to solve natural science problems. The more often he/she does so, the higher the probability he/she has natural wisdom. We can similarly use a mathematical formula to show how the elements of natural wisdom contribute to the development of natural wisdom: " $W n=C n \times M$ ", where "Wn" stands for "natural wisdom", "Cn" for "creativity in studying natural sciences", " $M$ " for "motivation”, and " $\times$ " for multiplication. The requirement on the level of motivation is not strict for natural wisdom. But the requirement on creativity in the process of solving-problem of "zuòshì" is stricter. With the same level of motivation, the more creative one is, the higher level of natural wisdom he will develop. If a person has high creativity but has no motivation in solving-problem of "zuòshì", he/she is only an intelligent person with high-IQ, but not a person of natural wisdom, because the product of natural wisdom is zero. This implies that while the primary element of natural wisdom is creativity, normative element should also be included. If an intelligent and morally virtuous person is good at using innovative, efficient and ingenious ways to solve problems in "zuòrén” and "zuòshì", he/she has both moral wisdom and natural wisdom simultaneously. 
(3) The ratios of subject element and object element in moral wisdom and natural wisdom are different. Moral wisdom contains mainly wisdom of "zuòrén”. People have to follow universal ethical principles, but they are also influenced by their cultures and traditions. Different cultures have developed differing ethical systems. While there are differences among them, they do share certain common values of morality. For this reason, moral wisdom not only possesses objectivity and universality, but also is culturally relative. In contrast, natural wisdom is wisdom of dealing with subjects of natural science, which aims to discover natural laws. While we need to construct subjectively theories of natural laws, the constructed theories are really a description of objective natural laws, which are not subject to the impact of culture factors.

(4) Natural wisdom and moral wisdom relate to different subject mattes. Generally speaking, pure natural science is a study of objective objects. The kind of wisdom employed in scientific inquiry, such as mathematics, chemistry, biology and astronomy, etc., is mainly natural wisdom. Humanities and social sciences study people-related phenomena, which essentially involve normative issues. The sort of wisdom employed in dealing with issues in these areas, such as music, fine arts, sociology, ethics, etc., is mainly moral wisdom. In the interdisciplinary study of sciences and humanities, the combination of moral wisdom and natural wisdom becomes necessary (Wang \& Zheng, 2011, pp. 310-312).

The connection between moral wisdom and natural wisdom. Moral wisdom and natural wisdom share similarities and have differences between them. Both of them integrate intelligence with morality as their constituent elements, but each corresponds to a distinct sort of abilities. More wisdom and natural wisdom are connected in a way that they strengthen each other when employed appropriately. If a person of moral wisdom recognizes and utilizes properly the impact of the natural laws on "zuòrén", he/she will do better on "zuòrén" and thus, gets his/her moral wisdom strengthened and improved. If he/she is very capable of natural science, he/she will have both moral wisdom and natural wisdom well developed and strengthened. Similarly, if a person of natural wisdom continues to gain knowledge of "zuòrén" and earnestly practice what he/she advocates, he/she will have her natural wisdom strengthened. If he/she makes accomplishments on "zuòrén”, he/she will have both moral wisdom and natural wisdom well developed and strengthened (Wang \& Zheng, 2011, p. 312).

There are five possible combinations of natural and moral wisdom, corresponding to five types of wise person: (1) The person with pure moral wisdom, such as Confucius; (2) The person with pure natural wisdom, such as Lu Ban in ancient China; (3) The person with more moral wisdom and less natural wisdom, such as Zhu Geliang in ancient China; (4) The person who has more natural wisdom than moral wisdom, such as Einstein; and (5) The person with equal natural and moral wisdom, such as Mozi in ancient China.

Though there is no agreed-upon criterion for measuring wisdom, wisdom can be different in quantitative magnitude. In everyday language, for instance, we talk about "small wisdom", "moderate wisdom" and "great wisdom". The three kinds of wisdom are united in that all of them integrate intelligence with morality as their constituents. The difference among them lies in quantitative magnitude. The amount of wisdom accumulates gradually, and the possession of great wisdom starts with possession of small wisdom. Distinguishing between levels of wisdom and recognizing the importance of small wisdom help one to develop and increase wisdom by self-cultivation and by education.

The five types of wisdom differ in quantity and quality. We might classify moderate and small wisdom into the category of quasi-wisdom and classify high-level wisdom into the category of true wisdom. True wisdom is wisdom with which one can make original insights beyond the existing knowledge attained by humankind, which may contribute to the advancement of human knowledge and civilization. Quasi-wisdom is 
wisdom with which one can make novel insights beyond what he/she already knows and thus add new knowledge to the stock of his knowledge. Therefore, while having similar psychological structure, true wisdom and quasi-wisdom differ in the scope of originality of their accomplishments. The combinations of the wisdom of different types and different levels of development can further result in sub-types of wisdom and sub-types of wisdom person. Each of the sub-types of wise person can be called a true great wise person, if his/her sub-type wisdom is developed to the maximum.

\section{Conclusions}

There are at least five advantages for us to define wisdom as integration of morality and intelligence: (1) to borrow and blend the merits of Chinese and Western classical viewpoints of wisdom; (2) to distinguish wisdom from cleverness, goodness, social intelligence and interpersonal intelligence, etc.; (3) to promote the education of wisdom; (4) to clarify that wisdom is both universal and relative to culture; and (5) to charter different kinds of wisdom. As the first four have been discussed, we will now discuss the last one.

As Robinson points out, western philosophers in ancient Greece classify wisdom from philosophical perspectives. For example, there are three types of wisdom in Plato's Dialogues: Sophia (theoretical wisdom), Prognosis (practical wisdom) and Episteme. Aristotle classified wisdom into two types: One is theoretikes, the other is practical wisdom (Sternberg, 1998, pp. 347-348). Though these classifications of wisdom have their own merits, they are far from precise and accurate. Kahn divides wisdom into two categories: conventional wisdom and emergent wisdom. Conventional wisdom applies to circumstances in which humanity is relatively well adapted to a stable set of existing physical and societal environments. However, significant changes in the physical or societal environment can render conventional wisdom inappropriate to the new set of conditions. It is at this point that emergent wisdom is needed to develop a new set of beliefs and rules for behaviors. In contrast with the stability provided by conventional wisdom, emergent wisdom strives to implement changes in thinking and behavior (Kahn, 2005, p. 42).

It is useful for us that Kahn classified wisdom in terms of the type of the environment. While his classification is insightful, it has two drawbacks. On the one hand, conventional wisdom is more likely to be the routine use of existing knowledge and cannot be properly described as wisdom, because it lacks the important characteristic of wisdom - innovation. On the other hand, classification of wisdom should take psychological mechanisms into consideration. It will not capture the essential nature of wisdom, if we only classify wisdom in terms of the types of the environment one adapts to. Nor can this classification capture the Chinese and Western insights on wisdom or develop a full understanding of the differences and similarities between different types of wisdom. In response, we classify wisdom into moral wisdom and natural wisdom for the first time in literature, which allows us to explore the differences and connections between them. The latter constitutes a merit of our new model of wisdom.

\section{References}

Baltes, P. B., \& Smith, J. (2008). The fascination of wisdom: Its nature, ontogeny, and function. Perspectives on Psychological Science, 3, 56-64.

Baltes, P. B., \& Staudinger, U. M. (1993). The search for a psychology of wisdom. In Current Directions in Psychological Science (Vol.2, pp. 75-80). London: Cambridge University Press.

Baltes, P. B., \& Staudinger, U. M. (2000). Wisdom: A metaheuristic (pragmatic) to orchestrate mind and morality toward excellence. American Psychologist, 55, 122-135. 
Cattell, R. B. (1963). Theory of fluid and crystallized intelligence: A critical experiment. Journal of Educational Psychology, 54(1), 1-22.

Erikson, E. H. (1959). Identity and the life cycle. New York: International Universities Press.

Feng, Q. (1996). Recognize the world and yourselves. Shanghai: Eastern Normal University Press.

Grieg, R., \& Zimbardo, P. (2003). Psychology and life (16th ed., L. Wang Trans.). Beijing: Posts \& Telecom Press.

Horn, J. L. (1965). Fluid and crystallized intelligence: A factor analytic study of the structure among primary mental abilities. (Unpublished doctoral dissertation, University of Illinois).

Horn, J. L., \& Cattell, R. B. (1966). Refinement and test of the theory of fluid and crystallized general intelligences. Journal of Educational Psychology, 57(5), 253-270.

Horn, J. L., \& Cattell, R. B. (1967). Age differences in fluid and crystallized intelligence. Acta Psychologica, 26, 107-129.

Huang, X. T. (2005). Psychology and life. Guangzhou: Jinan University Press.

Huang, X. T. (2007). Introduction to psychology (2nd ed.). Beijing: Peoples Education Press.

James, L. (1991). The works of Mencius. Taipei: SMC Publishing Inc..

Kahn, A. R. (2005). A way to wisdom: the next step. Revision, 28(1), 42-45.

Kohlberg, L. (1984). The psychology of moral development. Harper \& Row, Publishers, San Francisco.

Li, X. F. (Ed.). (2004). The collected works of Guan Zi. Beijing: Zhonghua Book Company.

Liang, S. M. (1999). Chinese-western culture and philosophy. Beijing: Shangwu Book Company.

Lin, S. Y. (2005). The difference of wisdom between the east and the west. Study Monthly, 5, 20.

Locke, J. (1999). On education (R. G. Fu Trans.). Beijing: Educational Science Press.

Lu, G. S. (1993). The English-Chinese dictionary. Shanghai: Shanghai Translation Publishing House.

Paris, S. G. (2001). Wisdom, snake oil, and the educational marketplace. Educational Psychologist, 36, 257-260.

Piaget, J. (1992). The psychology of intelligence (B. L. Hong Trans.). Beijing: China Social Science Press.

Sternberg, R. J. (1998). A balance theory of wisdom. Review of General Psychology, 2, 347-365.

Sternberg, R. J. (2001a). Why schools should teach for wisdom: The balance theory of wisdom in educational settings. Educational Psychologist, 36(4), 227-245.

Sternberg, R. J. (2001b). How wise is it to teach for wisdom? A reply to five critiques. Educational Psychologist, 36(4), $269-272$.

Sternberg, R. J. (2003). Wisdom, intelligence and creativity synthesized. New York: Cambridge University Press.

Sternberg, R. J. (2004a). Four alternative futures for education in the United States: It's our choice. School Psychology Review, 33(1), 67-78.

Sternberg, R. J. (2004b). Why smart people can be so foolish. European Psychologist, 9(3), 145-150.

Sternberg, R. J. (2004c). Words to the wise about wisdom? A commentary on Ardelt's critique of Baltes. Human Development, 47, 286-289.

Sun, Y. R. (Qing Dynasty) (Ed.). (2001). The collected works of Mo, Di. and his students. Beijing: Zhonghua Book Company.

Teaching and Researching Office of History of Foreign Philosophy (In Department of Philosophy of Peking University). (1981). Selected works of western philosophy. Beijing: Commercial Press.

Thilly, F. (1987). Introduction to ethics (Y. He Trans.). Beijing: University of Chinese people Press.

Wang, F. Y., \& Zheng, H. (2008). The Chinese culture psychology (3rd ed.). Guangzhou: Jinan University Press.

Wang, F. Y., \& Zheng, H. (2009). Wisdom derives from knowledge: The Chinese classical wisdom view. Journal of Nanjing Normal University (Social Science Edition), 4, 104-110.

Wang, F. Y., \& Zheng, H. (2010). Review five kinds of western key viewpoint about wisdom. Journal of Dialectics of Nature, 32(3), 93-97, 107.

Wang, F. Y., \& Zheng, H. (2011). A wisdom theory of integrating intelligence with morality. In F. Y. Wang, \& L. S. Yang (Eds.), A new education psychology (3rd ed., pp. 304-314). Guangzhou: Jinan University Press.

Wang, X. Q. (Ed.). (1988). The collected works of Xun Zi. Beijing: Zhonghua Book Company.

Whitehead, A. N. (2002). The aims of education (R. Z. Xu Trans.). Beijing: Sanlian Book Company.

Yang, B. J. (1980). Translated notes on the analects of Confucius. Beijing: Zhonghua Book Company.

Yang, S. Y., \& Sternberg, R. J. (1997). Conceptionions of intelligence in ancient Chinese philosophy. Journal of Theoretical and Philosophical Psychology, 17(2), 101-119. 